\title{
Selection Criteria for Supercapacitors Based on Performance Evaluations
}

\author{
Sang-Hyun Kim* and Woojin Choi ${ }^{\dagger}$ \\ $\dagger *$ Dept. of Electrical Engineering, Soongsil University, Seoul, Korea
}

\begin{abstract}
In this paper, criteria for better selection of a supercapacitor through EIS (Electrochemical Impedance Spectroscopy) experiments are presented. The performance characteristics of a supercapacitor are thoroughly analyzed in terms of losses and available energy to select the optimal product. The validity of the proposed criteria is demonstrated through the computer simulations and experiments on a fuel cell vehicle using a supercapacitor module with the FTP-72 urban dynamometer driving schedule.
\end{abstract}

Key Words: Electrochemical impedance spectroscopy, Fuel cell vehicle, Performance evaluation, Selection criteria, Supercapacitor

\section{INTRODUCTION}

Supercapacitors can improve the performance of a system that normally uses fuel cells or batteries because of their high power density. Their reliability, stability and environmentally friendly nature make them a good candidate for the next generation of energy storage devices [1]-[4]. Unlike conventional batteries, which produce energy through an electrochemical reaction, supercapacitors produce energy through a physical phenomenon, whereby energy is stored and released through the adsorption and desorption of ions, occurring at the interface of an electrode and electrolyte [1]. This simplicity results in several desirable characteristics for a device with excellent energy-storage properties such as a long cycle life and a high specific power density [5]. Due to their porous electrodes, supercapacitors can store far more energy than conventional capacitors such as electrolytic capacitors. In addition, charging and discharging can take place at extremely high rates, making them highly efficient. They can be used in applications where there is energy to be captured through repetitive motions and where load leveling is required for low power density devices such as fuel cells and batteries, thereby enhancing the efficiency and reliability of the system. Also, they can compensate for their slow response by accommodating the overload or peak power demands, thereby protecting the main energy source of the system. Thounthong et al. presented a control strategy for a fuel cell hybrid source using supercapacitors as an auxiliary source [6] and M. Uzunoglu et al. proposed a novel wavelet based load sharing algorithm for the hybrid vehicular power systems [7].

Manuscript received Jul. 30, 2011; revised Dec. 9, 2011

Recommended for publication by Associate Editor Tae-Woong Kim.

$\dagger$ Corresponding Author: cwj777@ssu.ac.kr

Tel: +82-2-860-0652, Fax: +82-2-817-7961, Soongsil University

* Dept. of Electrical Engineering, Soongsil University, Korea
Large-capacity supercapacitors are mostly made up of many cells connected to each other. There is a wide variety of supercapacitors on the market with different technical characteristics and prices. It is therefore important to select the most efficient product and to have a good understanding of its characteristics.

There have been several attempts to experimentally analyze and model the internal properties of supercapacitors. For example, an equivalent circuit model of a supercapacitor using three RC branches was proposed by L. Zubieta [8]. H. Gualous et al. analyzed the variations in the series resistance and capacitance values of supercapacitors depending on the temperature [9]. However, most of these analyses involve DC tests, making it difficult to study the characteristics that depend on device voltage. This can be avoided by using electrochemical impedance spectroscopy (EIS), an AC test method of dividing the spectrum into real and imaginary components and calculating the capacitance from the latter. S. Buller et al. applied EIS when developing a dynamic model of a supercapacitor and succeeded in obtaining a highly accurate model [10].

This paper proposes criteria for evaluating the performance of supercapacitors and for selecting the best product on the basis of EIS, a non-destructive test, by comparing their dynamic characteristics through equivalent circuit modeling. Furthermore, the most efficient and economical product for a certain application is chosen on the basis of the experimental results and applied to the supercapacitor module design. Unfortunately, a supercapacitor with outstanding characteristics is very costly. Since supercapacitors are used in modules with numerous cells connected in series and parallel, economic module design is very important. EIS measurements were performed on products from different manufacturers and the most suitable was selected.

This paper performs EIS experiments on products taken 
from different manufacturers, selects the product most suitable for a fuel cell vehicle application, and presents a valid example for sizing the module by using the characteristics of the supercapacitor obtained through the analysis of the EIS results. In order to verify the usefulness of the proposed selection method, the North American standard vehicles driving duty cycle, FTP-72 UDDS, was used in the simulation and experiments.

\section{SUPERCAPACITOR IMPEDANCE Modeling}

\section{A. Electrochemical Impedance Spectroscopy}

For charge/discharge and current perturbation purposes, a bipolar power supply unit (model BP4610, NF Company) was used [11]. The measurement equipment and the software used for the EIS were developed in the laboratory [12] by the authors of this paper. In the developed system, a sensing circuit, LabVIEW 8.6 and a PCI-6154 were used to measure and record the voltage and current of supercapacitors on a real-time basis. The PCI-6154 is a simultaneous sampling multifunction I/O device for PCI bus computers from National Instruments [13]. It is an isolated PCI device featuring four isolated differential 16-bit analog inputs, four isolated 16bit analog outputs, six DI lines, four DO lines, and two general-purpose 32-bit counter/timers. All of the A/D and D/A converters are capable of $250 \mathrm{kS} / \mathrm{s}$ for each channel. Digitized data were acquired by the software and the signal was extracted using a digital lock-in amplifier. The impedance spectrum was then plotted.

The EIS, a method that perturbs a device and analyzes its response, was performed by limiting the magnitude of the applied perturbation current to below $2 \%$ of the charge in order to ensure the linear behavior, where $\mathrm{I}_{a}$ is the magnitude of the perturbation current, $f$ is the frequency of the current perturbation, $\mathrm{C}_{\text {rated }}$ is the rated capacitance, and $\mathrm{V}_{\text {rated }}$ is the rated voltage.

$$
I_{a}<0.02 \times \pi f C_{\text {rated }} V_{\text {rated }} .
$$

The experiments were performed at room temperature. Six different voltages ranging from $0 \%$ to $100 \%$ at intervals of $20 \%$, at frequencies ranging from $0.01 \mathrm{~Hz}$ to $1 \mathrm{kHz}$ were used. Products made by four different companies were selected. Fig. 1 shows a Nyquist impedance plot and a Bode plot for the product from Company A $(2.7 \mathrm{~V}, 2600 \mathrm{~F})$. The results indicate that as the charge increases, the real component of the impedance increases and the magnitude of the imaginary component decreases.

\section{B. Equivalent Impedance Modeling of a Supercapacitor}

The impedance of a supercapacitor can be expressed in terms of an ionic resistance placed in series with the impedance of a porous electrode, $Z_{\text {pore }}$. An impedance model for a porous electrode made up of a ladder circuit in which $\mathrm{R}^{\prime}{ }_{e} \mathrm{dx}$ and $\mathrm{C}^{\prime}{ }_{d} \mathrm{dx}$ are connected in parallel has already been proposed by De Levie et al. [14]. R' ${ }_{e}$ and $\mathrm{C}^{\prime}{ }_{d}$ are the electrolyte resistance and the electric double-layer capacitance per unit length $(\mathrm{dx})$ of the pore. By adding the resistance component and the inductance due to the external elements,
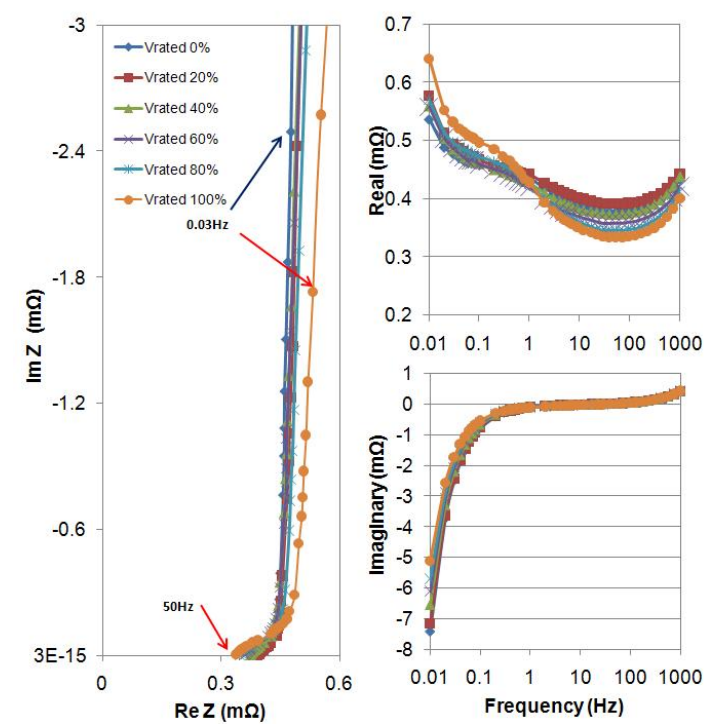

Fig. 1. Nyquist impedance plot of the supercapacitor by manufacturer A [0\%$\left.100 \% \mathrm{~V}_{\text {rated }}, 20^{\circ} \mathrm{C}\right]$.

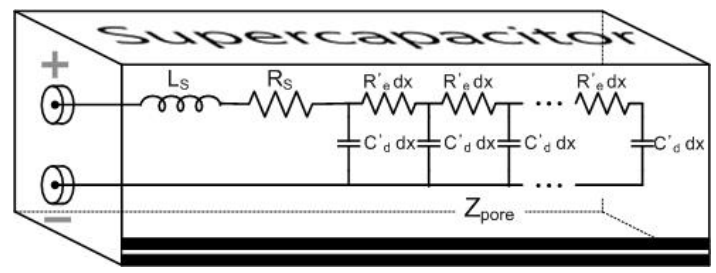

Fig. 2. Equivalent Impedance Modeling of the Supercapacitor.

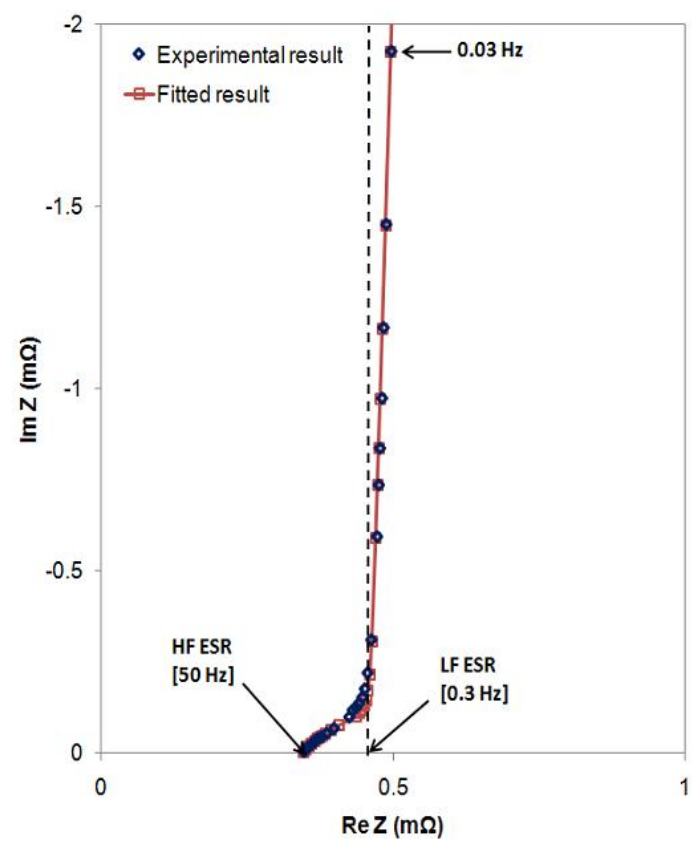

Fig. 3. Nyquist impedance plot of the supercapacitor by manufacturer A and its fitted result. 
TABLE I

FitTed PARAmeter of THE SUPERCAPACITOR By MANUfacturer A $\left[0-100 \% \mathrm{~V}_{\text {rated }}, 20^{\circ} \mathrm{C}\right]$.

\begin{tabular}{|c|c|c|c|c|c|}
\hline $\begin{array}{c}\mathrm{V}_{\text {rated }} \\
(\%)\end{array}$ & $\begin{array}{c}\mathrm{L}_{s} \\
(\mathrm{nH})\end{array}$ & $\begin{array}{c}\mathrm{R}_{s} \\
(\mathrm{mOhm})\end{array}$ & $\begin{array}{c}\mathrm{R}_{e} \\
(\mathrm{mOhm})\end{array}$ & $\mathrm{Q}_{d}$ & $\mathrm{~d}$ \\
\hline 0 & 65.8 & 0.364 & 0.250 & 2106 & 0.9924 \\
\hline 20 & 65.8 & 0.376 & 0.240 & 2159 & 0.9893 \\
\hline 40 & 65.8 & 0.360 & 0.264 & 2359 & 0.9890 \\
\hline 60 & 65.8 & 0.343 & 0.322 & 2526 & 0.9886 \\
\hline 80 & 65.8 & 0.329 & 0.393 & 2704 & 0.9879 \\
\hline 100 & 65.8 & 0.318 & 0.509 & 2987 & 0.9837 \\
\hline
\end{tabular}

the equivalent impedance model of the supercapacitor becomes a series circuit with an equivalent series inductance $\mathrm{L}_{s}$, an equivalent series resistance $\mathrm{R}_{s}$, and a pore impedance, $\mathrm{Z}_{\text {pore }}$, as can be seen in Fig. 2. Thus, a mathematical model of the supercapacitor can be expressed by (2), where $\mathrm{R}_{e}$ and $\mathrm{C}_{d}$ are the electrolyte resistance in the pore and the electric doublelayer capacitance, respectively [10].

$$
Z_{S C}=j \omega L_{s}+R_{s}+\sqrt{\left(\frac{R_{e}}{j \omega C_{d}}\right)} \operatorname{coth} \sqrt{j \omega R_{e} C_{d}} .
$$

Fig. 3 shows a Nyquist impedance plot of the product from Company A, measured at $80 \% \mathrm{~V}_{\text {rated }}$, and its fitted curve. The EIS indicates that in the high-frequency range $(0.3-50$ $\mathrm{Hz}$ ), the higher the frequency, the faster the convergence of the impedance to $\mathrm{R}_{s}$, the high-frequency equivalent series resistance (HF ESR). This is due to the porous electrode of the supercapacitor. The real component of this range coincides with $\mathrm{R}_{e}$, the electrode resistance. The impedance of an ideal supercapacitor would converge asymptotically to a line parallel to the imaginary axis, since only the imaginary component increases with the frequency, as shown in (3) at low frequencies.

$$
Z_{S C(\omega \rightarrow 0)}=R_{S}+\frac{R_{e}}{3}+\frac{1}{j \omega C_{d}} .
$$

However, the experimental results show that the impedance curve is slightly inclined. This is because the electric doublelayer capacitor of the porous electrode is closer to a constant phase element (CPE) than a purely capacitive component. Therefore, the equivalent circuit of supercapacitor can be expressed as in (4) by replacing the pure capacitance $\mathrm{C}_{d}$ in (2) with a CPE using $\mathrm{Q}_{d}$, its magnitude and $\mathrm{d}$, the exponent. Eq. (4) can be approximated for low frequencies by (5) [15]. At low frequencies, because the real component of the impedance increases with a decreasing frequency, the impedance curve bends slightly toward the real axis. The coefficient $d$ in (5) represents this tendency. Fig. 3 shows a good agreement between the measured impedance and the model. Table I shows the parameter variation obtained from the EIS tests performed at $0 \% \sim 100 \% \mathrm{~V}_{\text {rated }}$, with the product of company A.

$$
\begin{gathered}
Z_{S C}=j \omega L_{s}+R_{S}+\sqrt{\left(\frac{R_{e}}{(j \omega)^{d} Q_{d}}\right)} \operatorname{coth} \sqrt{(j \omega)^{d} R_{e} Q_{d}} \\
Z_{S C(\omega \rightarrow 0)}=R_{s}+\frac{R_{e}}{3}+\frac{1}{(j \omega)^{d} Q_{d}} .
\end{gathered}
$$

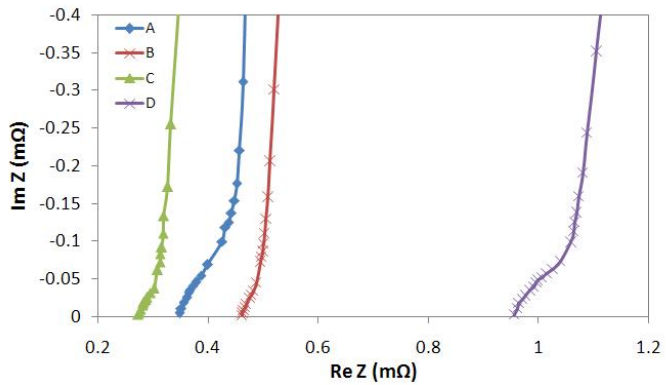

Fig. 4. Nyquist impedance plots of the supercapacitors for different manufacturers [80\% Vrated, $20^{\circ} \mathrm{C}$.

TABLE II

FitTed Parameter of THE SUPERCAPACITOR FOR EACH MANUFACTURER $\left[80 \% \mathrm{~V}_{\text {rated }}, 20^{\circ} \mathrm{C}\right]$.

\begin{tabular}{|c|c|c|c|c|c|}
\hline & $\begin{array}{c}\mathrm{L}_{s} \\
(\mathrm{nH})\end{array}$ & $\begin{array}{c}\mathrm{R}_{s} \\
(\mathrm{mOhm})\end{array}$ & $\begin{array}{c}\mathrm{R}_{e} \\
(\mathrm{mOhm})\end{array}$ & $\mathrm{Q}_{d}$ & $\mathrm{~d}$ \\
\hline $\mathrm{A}$ & 65.8 & 0.329 & 0.393 & 2704 & 0.9879 \\
\hline$B$ & 14.6 & 0.370 & 0.233 & 2506 & 0.9523 \\
\hline$C$ & 56.3 & 0.260 & 0.164 & 2965 & 0.9659 \\
\hline$D$ & 54.8 & 0.944 & 0.414 & 2279 & 0.9484 \\
\hline
\end{tabular}

\section{Supercapacitor Performance Characteristics}

It is possible to evaluate the performance of the supercapacitor by the equivalent circuit parameters obtained through electrochemical impedance spectroscopy. The criteria for performance evaluation include; the magnitude of the equivalent series resistance that causes a power loss, the variation of the capacitance depending on the state of the charge that causes a variation of the available energy and the coefficient $\mathrm{d}$ of the CPE that affects the self-discharge and thus the charge/discharge efficiency.

Fig. 4 shows Nyquist impedance plots corresponding to $80 \%$ $\mathrm{V}_{\text {rated }}$ of high-capacitance supercapacitors from four different manufacturers (Company A: 2.7 V, 2600 F; Company B: $2.8 \mathrm{~V}$, 3000 F; Company C: 2.7 V, 3500 F; Company D: 2.5 V, 2700 F) that have similar capacitance values. The results show that the high-frequency equivalent series resistance is lowest for Company $\mathrm{C}$, and that the impedance plot in the low-frequency range is most nearly vertical for Company A. The verticality of the curve indicates that the coefficient $\mathrm{d}$ for the supercapacitor equivalent circuit is close to 1 , and that the porous impedance of the product from Company A is most purely capacitive. Table II shows the values of the parameters obtained from the EIS results performed at $80 \% \mathrm{~V}_{\text {rated }}$ for each product.

\section{A. Power Loss and ESR}

The equivalent internal series resistance of a supercapacitor depends on its terminal voltage and make. Therefore, if a supercapacitor is used dynamically at $50 \%-100 \% \mathrm{~V}_{\text {rated }}$, the dissipated power may differ.

Both the series and electrolyte resistances in Table I indicate that the values differ by make and terminal voltage. The resistive component in the low-frequency regime (LF ESR; low-frequency equivalent series resistance) and the power dissipated are expressed as:

$$
R_{S C}(\omega \rightarrow 0)=R_{s}+\frac{R_{e}}{3}
$$




$$
P_{\text {loss }}=I^{2} \times\left(R_{s}+\frac{R_{e}}{3}\right)
$$

where, I is the current through the supercapacitor. Therefore, greater the HF ESR $\left(\mathrm{R}_{s}\right)$ and the electrolyte resistance in the pore $\left(\mathrm{R}_{e}\right)$, the greater the power loss [16].

\section{B. Available Energy and Capacitance Variation}

The capacitance of a supercapacitor can be calculated from the imaginary component (ImZ) of the impedance determined from EIS. However, in the EIS experiments it is crucial to use low frequencies $(<0.01 \mathrm{~Hz})$ for the perturbation, because the magnitude of capacitance varies according to the frequency and converges to a constant value in the low-frequency regime. This is due to the fact that the ions cannot follow the applied electric field and do not reach the depth of the electrode pores if the perturbation frequency is not low enough [17].

$$
\text { Capacitance }=1 / \omega\left(\omega L_{s}-\operatorname{Im} Z\right) \text {. }
$$

Fig. 5 shows the capacitance plotted as a function of the voltage at $0.01 \mathrm{~Hz}$ for the different manufacturers. Companies $\mathrm{B}, \mathrm{C}$ and $\mathrm{D}$ do not show little increases in the capacitance with respect to the voltage, whereas Company A shows a $30 \%$ increase between $0 \%$ and $100 \% \mathrm{~V}_{\text {rated }}$. This feature is very important for calculating the available energy.

In most applications, a supercapacitor releases its charge from $100 \%$ to $50 \% \mathrm{~V}_{\text {rated }}$. Thus, if the capacitance is constant, the available energy is $75 \%$ of the stored energy, as demonstrated below. However, since the capacitance does change with the voltage and also differs by make, the available energy $\mathrm{E}_{A}$ should be calculated using (10).

$$
\begin{gathered}
E_{A}=\frac{1}{2} C_{\text {rated }}\left(V_{\text {rated }}^{2}-\left(0.5 V_{\text {rated }}\right)^{2}\right) \\
E_{A}=\frac{1}{2} C_{100 \% V_{\text {rated }}} V_{\text {rated }}^{2}\left(1-0.25 \times \frac{C_{50 \% V_{\text {rated }}}}{C_{100 \% V_{\text {rated }}}}\right) .
\end{gathered}
$$

Thus, the greater the change in capacitance, the greater the available energy. It is also useful to define the normalized quantity $\mathrm{E}_{V}$ as:

$$
E_{V}=1-0.25 \times \frac{C_{50 \% V_{\text {rated }}}}{C_{100 \% V_{\text {rated }}}} .
$$

C. Influence of the ' $d$ ' parameter on the self-discharge and the charge/discharge efficiency

A CPE is the component of an equivalent circuit that most strongly influences the characteristics of a supercapacitor. A CPE represents the self-discharging phenomenon caused by diffusion and appears on a Nyquist plot at an angle to the right side of the vertical axis in the low-frequency region [18].

In order to observe the self-discharge characteristics of a supercapacitor, experiments were performed, as can be seen in Fig. 6. After charging from $0 \%$ to $100 \% \mathrm{~V}_{\text {rated }}$ using a constant current of $10 \mathrm{~A}$, the charging cable was removed and the voltage change was measured for over 15,000 s. The product from Company A, with $d=0.9837$, showed the smallest self-discharge with a final $\mathrm{V}_{\text {rated }}$ of $96.0212 \%$. The

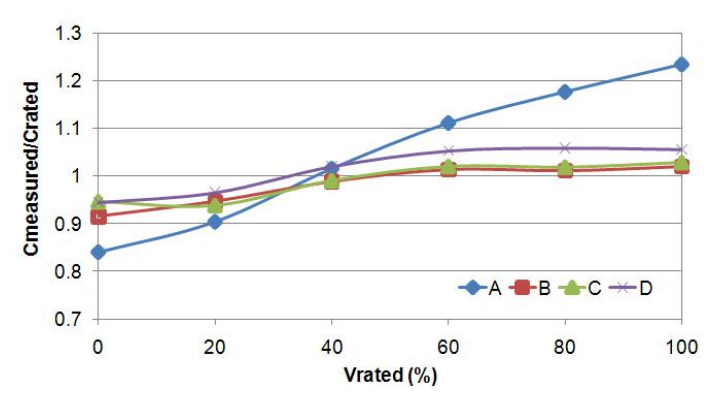

Fig. 5. Variation of the capacitance at each $\mathrm{V}_{\text {rated }}$ by make.

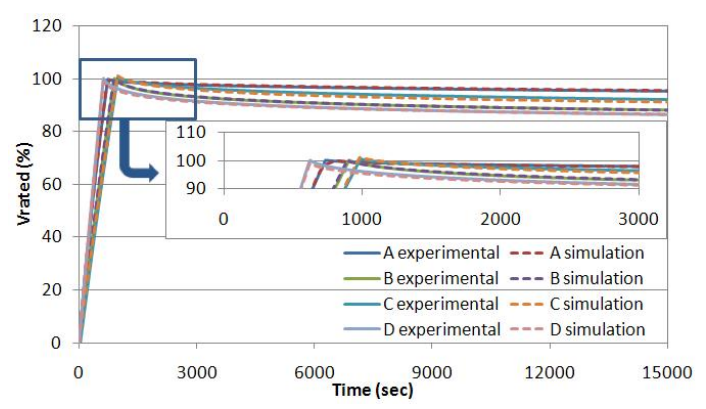

Fig. 6. Self-discharge experiment and simulation of charge and self-discharge voltage by each product.

product from Company $\mathrm{D}$, with $d=0.9418$, showed the largest self-discharge with a final $\mathrm{V}_{\text {rated }}$ of $86.3433 \%$.

Accurate simulations of the charge/discharge efficiency can then be performed. A simulation was made using Matlab/Simulink to analyze the voltage response of the supercapacitor for each product. The voltage response was calculated using (12), where $\Gamma$ is the gamma function, and $I_{c}$ is the constant current [19]. The simulation shows the natural discharging from the fully charged state, after the supercapacitor was charged with a current $\left(\mathrm{I}_{c}\right)$ of $10 \mathrm{~A}$ to $100 \% \mathrm{~V}_{\text {rated }}$. The current was blocked at $100 \% \mathrm{~V}_{\text {rated }}$ to observe the changes in voltage. The charging current was expressed as a step function, and the resulting expression for the response voltage is given by (13), where $\mathrm{V}_{i}$ is the initial voltage, $\mathrm{H}$ is the step function, and $\mathrm{t}_{\text {cut }-o f f}$ is the time the current is blocked.

$$
\begin{gathered}
v_{S C}(t)=I_{c} \times\left(R_{s}+\frac{R_{e}}{3}+\frac{t^{d}}{Q_{d} \Gamma(1+d)}\right) \\
v(t)=V_{i}+I_{c} \times\left(R_{s}+\frac{R_{e}}{3}+\frac{t^{d}-\left(t-t_{\text {cut }-o f f}\right)^{d} \cdot H\left(t-t_{\text {cut }-o f f}\right)}{Q_{d} \cdot \Gamma(1+d)}\right) .
\end{gathered}
$$

As can be seen in Fig. 6, the test results for the selfdischarge phenomenon agree well with the simulation results, indicating that this phenomenon can be simulated very accurately. In addition, it was found that this phenomenon becomes more pronounced with a decrease in the value of $d$.

Fig. 7 shows a pie chart that indicates the charge/discharge loss between $50 \%$ and $100 \% \quad \mathrm{~V}_{\text {rated }}$. In this experiment the charge and discharge rates were selected to be $0.0004 \mathrm{C}_{\text {rated }} \mathrm{V}_{\text {rated }} / \mathrm{s}$ as suggested by the IEC $62391-1$ standard. The charge/discharge efficiency is $92.86 \%$, with the resistance loss (obtained by equation (7)) being $0.25 \%$ and the loss from the CPE characteristics being $4.89 \%$. Furthermore, it was found that the loss from the CPE has a greater impact on the charge/discharge efficiency than the resistance. However, 


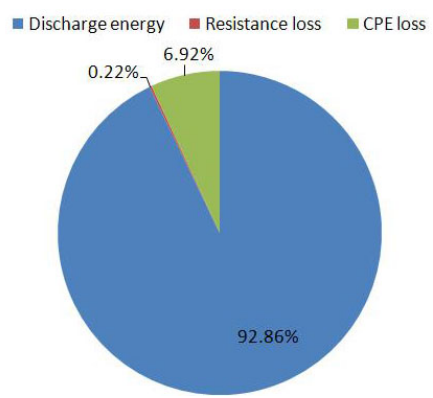

Fig. 7. Charge/Discharge loss analysis of the supercapacitor by company A.

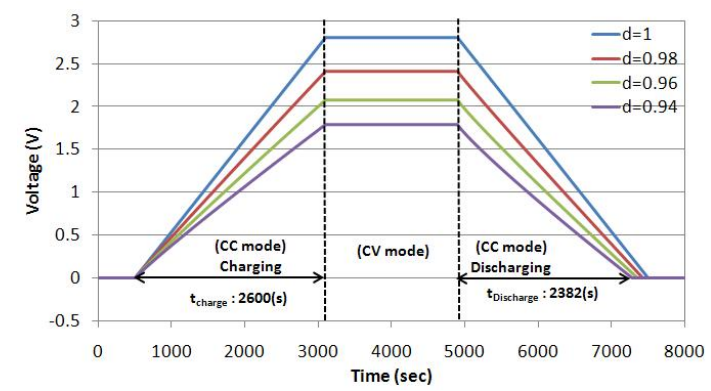

Fig. 8. Simulation of charge/discharge voltage by the changes in coefficient $d\left(\mathrm{I}_{c}=2.8 \mathrm{~A}, \mathrm{Q}_{d}=2600, \mathrm{LF} \mathrm{ESR}=0.5 \mathrm{~m} \Omega\right)$.

it should be noted that the resistive loss could be bigger than the CPE loss at high charge/discharge rates.

As can be seen in Fig. 8, the charge/discharge simulation was performed using the model of (5) while changing the coefficient d. Here, $\mathrm{Q}_{d}=2600$ and the LF ESR was 0.5 $\mathrm{m}$. The charging time increases with decreasing values of $d$, implying a greater power loss, especially in the region with a high $\mathrm{V}_{\text {rated }}$. The electric double-layer capacitance behaves more like a pure capacitor and shows linear charge/discharge characteristics with little loss as $\mathrm{d}$ approaches 1 . There is less loss for higher values of $d$.

Fig. 9 compares the charge/discharge response to a square wave current from the simulation result for the product of Company A. For the charge/discharge experiments, the supercapacitor voltage was maintained at $0 \mathrm{~V}$ using a bidirectional power supply for 10 minutes before charging. The charge and discharge were performed with a current of $0.0004 \mathrm{C}_{\text {rated }} \mathrm{V}_{\text {rated }} / \mathrm{s}$. The rated voltage was then maintained by floating charge for 30 minutes. Then, the efficiency of the charge/discharge was calculated while discharging with the same current.

As can be seen in the figure, the charging required a time of 2,645s and the discharging required 2,602s, which implies an energy loss. As mentioned in the previous section, since the supercapacitor operates between $50 \%$ and $100 \% \mathrm{~V}_{\text {rated }}$, the charge/discharge efficiency must also be considered in this range. Accordingly, the efficiency was calculated as a ratio of the charging energy from $50 \%$ to $100 \% \mathrm{~V}_{\text {rated }}$ to the discharging energy from $100 \%$ to $50 \% \mathrm{~V}_{\text {rated }}$, as can be seen in Fig. 10. The charge and discharge energies and the charge/discharge efficiency were calculated as $8,627 \mathrm{~J}, 8,009$ $\mathrm{J}$, and $92.86 \%$, respectively.

In the simulation, in order to reflect the changes in the equivalent impedance model with the voltage, each parameter extracted from the Nyquist plot, obtained at six different

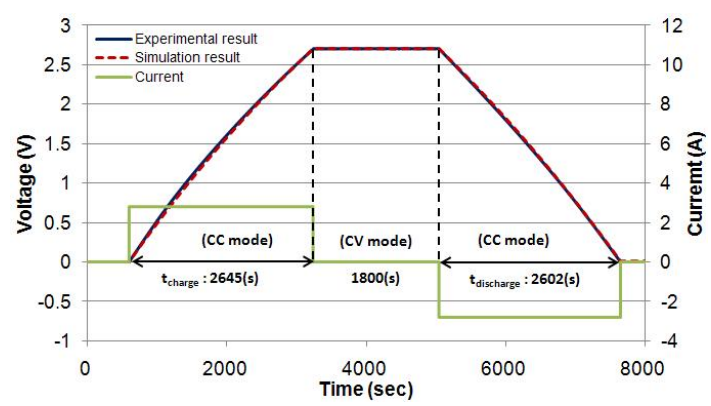

Fig. 9. Result of charge/discharge experiment and simulation by manufacturer A.

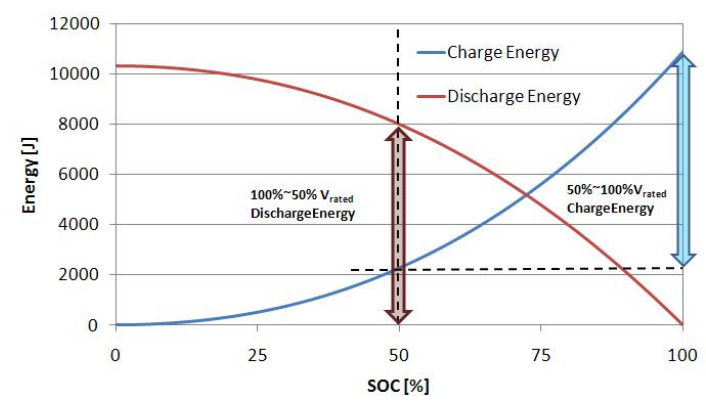

Fig. 10. The ratio the charge energy and the discharge energy.

voltages, in Fig. 1, were fitted onto a curve. Then, varied values of these parameters with voltages were used to calculate the results at every iterative step of the simulation, as can be seen in Fig. 9.

\section{Optimal Product Selection}

Table III compares the specific energy, the energy density, the charge/discharge efficiency, the ratio of the remaining charge after self-discharge for 15000 s and the capacitance change of the supercapacitor by manufacturer. The discharging energy in going from $100 \%$ to $50 \% \mathrm{~V}_{\text {rated }}$ was again used as the reference in calculating the specific energy and the energy density.

Table III shows a small difference between the calculated $\left(\mathrm{E}_{V}\right)$ and the measured $\left(\mathrm{E}_{V_{-} E X}\right)$ ratios of the available energy that results from the higher charged condition, and hence from a higher resistive component and a strong self-discharge effect. Also, the product of Company A, which has the highest capacitance change, shows the highest value of the measured ratio of available energy $\left(\mathrm{E}_{V_{-} E X}\right)$.

Fig. 11 compares the performance by product by using a spider map. The product of Company A was considered to be optimal because it had a small ESR, a high remaining charge after self-discharge, a high-efficiency charge/discharge, and a high specific energy and energy density.

From an overall view of the above results, the two major elements that determine loss in a supercapacitor are the coefficient $\mathrm{d}$ of the CPE, and the equivalent series resistance. However, the equivalent series resistance of a supercapacitor has an extremely small value of several hundred $\mu \Omega$, and the loss from this resistance is also small. As Table I shows, the diffusion loss expressed by $\mathrm{d}$ is very large. Therefore, it is most important to choose the product with $\mathrm{d}$ that is closest to 1 when selecting an optimal supercapacitor. At the same time, 
TABLE III

COMPARISON OF SUPERCAPACITOR CHARACTERISTICS

\begin{tabular}{|c|c|c|c|c|}
\hline & $\mathrm{A}$ & $\mathrm{B}$ & $\mathrm{C}$ & $\mathrm{D}$ \\
\hline $\mathbf{V}_{\text {rated }}(\mathbf{V})$ & 2.7 & 2.8 & 2.7 & 2.5 \\
\hline $\mathbf{C}_{\text {rated }}(\mathbf{F})$ & 2600 & 3000 & 3500 & 2700 \\
\hline $\mathbf{C}_{V}$ & 0.8178 & 0.9813 & 0.9775 & 0.9817 \\
\hline $\mathbf{E}_{V}$ & 0.7955 & 0.7547 & 0.7556 & 0.7546 \\
\hline $\mathbf{E}_{V} E X$ & 0.7743 & 0.7429 & 0.7378 & 0.7374 \\
\hline $\begin{array}{c}\text { Charge/discharge } \\
\text { Efficiency (\%) }\end{array}$ & 92.86 & 86.50 & 91.05 & 74.20 \\
\hline $\begin{array}{c}\text { Specific energy } \\
\text { (Wh/kg) }\end{array}$ & 4.6866 & 3.858 & 3.8536 & 3.9219 \\
\hline $\begin{array}{c}\text { Energy density } \\
\text { (Wh/L) }\end{array}$ & 6.8282 & 5.1824 & 5.1270 & 4.2361 \\
\hline $\begin{array}{c}\text { Remaining charge } \\
\text { after } \\
\text { self-discharge (\%) }\end{array}$ & 95.4577 & 88.0474 & 92.0407 & 86.3433 \\
\hline
\end{tabular}

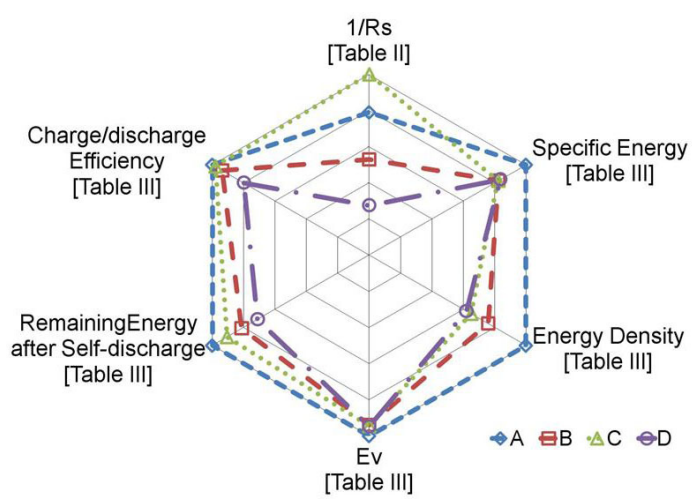

Fig. 11. Spider map for the performance evaluation of the supercapacitors.

the composition of economically feasible modules becomes possible only if a relatively large available energy can be used with a product that shows a large change in capacitance by voltage.

\section{Verification of the Usefulness of the PROPOSED SELECTION CRITERIA}

In this section, a valid design example of a supercapacitor module for a fuel cell vehicle is presented and computer simulations and experiments are performed in order to verify the usefulness of the proposed selection criteria. For the simulation, a fuel cell vehicle system was composed by using LabVIEW, as shown in Fig. 12, and the FTP-72 Urban Dynamometer Driving Schedule (UDDS).

\section{A. Fuel Cell Vehicle Simulation Using the FTP-72 UDDS}

The specifications of the fuel cell vehicle used in the simulations are set to weight $980 \mathrm{~kg}$, front area 'A' $1.5 \mathrm{~m} 2$, gear ratio ' $G$ ' 13 , tire radius ' $r$ ' $0.275 \mathrm{~m}$, rolling resistance coefficient $\mu \mathrm{rr} 0.015$, and air density $\rho 1.25 \mathrm{~kg} / \mathrm{m} 3$. To find out the number of cells for the composition of the supercapacitor, the amount of energy needed to drive the FTP-72 UDDS was calculated. The input/output power characteristics of the motor needed to drive the UDDS can be expressed as the product of the total traction force and the angular velocity as in (14) [20]. Fig. 13 shows the speed profile of the FTP-72 UDDS, and the total power calculated by using (14) in Fig. 14.

A supercapacitor, used with a main energy source like a fuel cell as an auxiliary energy storage device, plays the role of handling the peak power of the system. Since the fuel cell

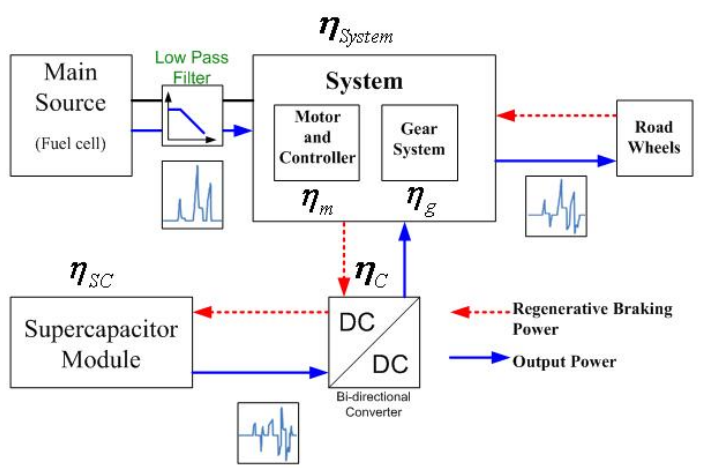

Fig. 12. Block diagram of the fuel cell vehicle.

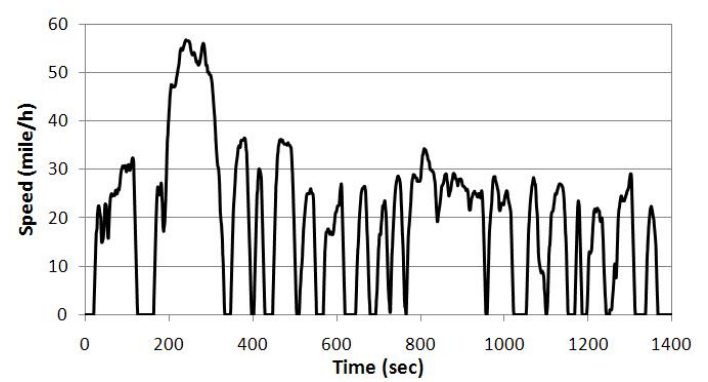

Fig. 13. FTP-72 Urban Dynamometer Driving Schedule (UDDS).

generates power by a chemical reaction, it is impossible to increase the power at a faster rate than that of the chemical reaction [6]. Thus the rate of the power change in the fuel cell output has to be limited for reliable operation. A low pass filter is used to filter out the high frequency component of the power command in the simulation. The low pass filter was designed to have 8 seconds time constant, thereby preventing the rate of the power change from exceeding $2.37 \mathrm{~kW} / \mathrm{sec}$ for the $30 \mathrm{~kW}$ fuel cell stack used in the simulations. However, the time constant may vary depending on the performance of the fuel cell as well as the control strategy, and this will eventually affects the size of the supercapacitor module. Therefore, the fuel cell stack only takes the low frequency component of the required output power, as can be seen in Fig. 15. In addition, the supercapacitor takes care of the high frequency component and the regenerated energy from the vehicle when decelerating and braking. Therefore, the charge/discharge power of the supercapacitor is calculated as in (15).

$$
\begin{gathered}
P_{\text {total }}=144.06 \mathrm{~V}+0.35 \mathrm{~V}^{3}+1029 \frac{d v}{d t} V \\
P_{S C}=\frac{1}{\eta_{\text {System }}} P_{\text {peak }}+\eta_{\text {System }} \eta_{S C} P_{\text {regeneration }} .
\end{gathered}
$$

For accurate calculations, in the case where energy is charged/discharged at the supercapacitor, the supercapacitor efficiency $\left(\eta_{s c}\right)$ and the system efficiency $\left(\eta_{s y s t e m}\right)$ both were considered. The system efficiency considered the motor and controller efficiency $\left(\eta_{m}\right)$, the gear system efficiency $\left(\eta_{g}\right)$ and the power converter efficiency $\left(\eta_{c}\right)$. The total value was calculated to be about 0.7 . Therefore, the input/output power of the supercapacitor is the value in which the efficiency is applied to the regenerated power, the high frequency component and low frequency component of the total power and it is expressed in 


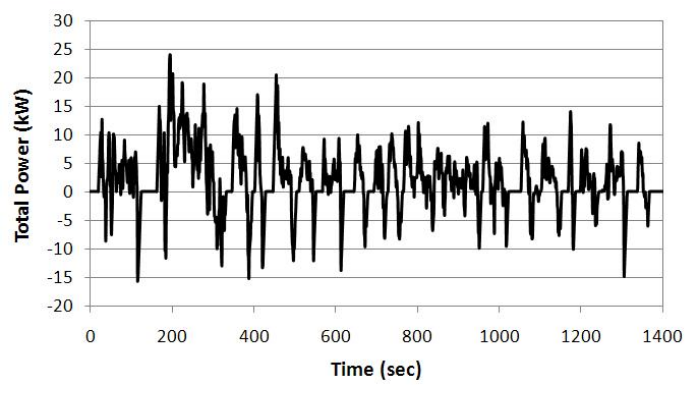

Fig. 14. Total power profile for FTP-72 UDDS.

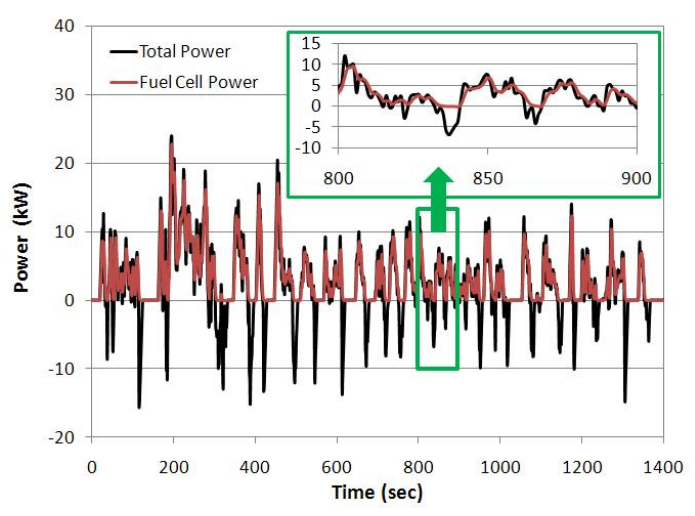

Fig. 15. Total power and fuel cell profile FTP-72 UDDS.

Fig. 16. The supercapacitor module was fully charged before starting the simulation and it was charged only by regenerative energy during the course of the simulation.

\section{B. Design and Comparison of the Supercapacitor Modules}

The energy of supercapacitor can be expressed by integrating the power of Fig.16 as in Fig.17, and the difference between the minimum value and the maximum value becomes the amount of energy $\left(\mathrm{E}_{\text {needed }}\right)$ needed for the sizing of the supercapacitor module. Therefore, if the supercapacitor module is designed for a fuel cell vehicle to drive the FTP72 UDDS, $177.5 \mathrm{~kJ}$ is needed. From this value, the number of supercapacitor cells needed is determined, and an actual supercapacitor is used to get discharged only up to $50 \% \mathrm{~V}_{\text {rated }}$, so that the number is calculated as in (16) by the available energy $\left(\mathrm{E}_{A_{-} E X}\right)$ measured by the experiment. Therefore, when using the product of Company A, driving the FTP-72 requires 23 cells.

$$
N_{s}=\frac{E_{\text {needed }}}{E_{A_{-} E X}} .
$$

Since the maximum output current of the supercapacitor is limited typically by $12 \%$ of the short circuit current [21], it is first necessary to check if the maximum output current exceeds this level when implementing a module. If the maximum output current of the supercapacitor for the FTP-72 UDDS meets the requirement, then the series connection is recommended to increase the module voltage. Since higher efficiency in the energy conversion process can be obtained in the higher voltage and lower current condition, it is recommended that the module be connected in series to get a higher voltage as long as it is allowed by the system design. Thus, the terminal voltage and the capacitance of the module are calculated as in

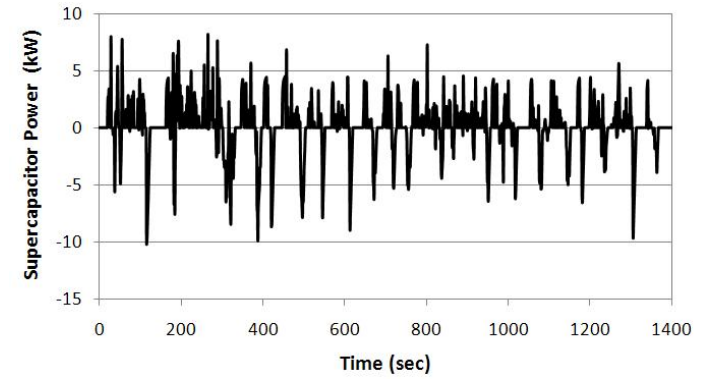

Fig. 16. Power profile of the supercapacitor for FTP-72 UDDS.

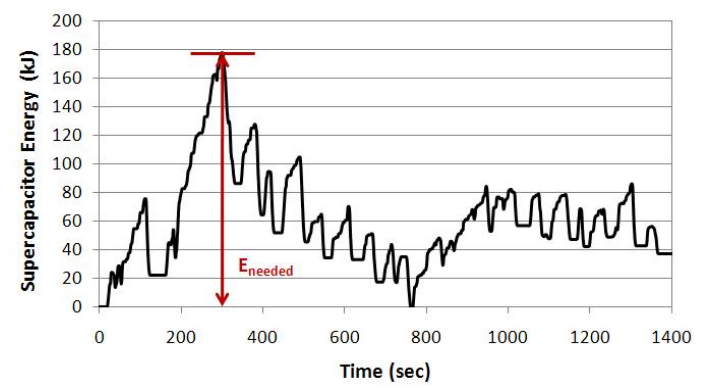

Fig. 17. Energy profile of the supercapacitor for FTP-72 UDDS.

(17) and (18).

$$
\begin{gathered}
V_{T_{-} \text {Module }}=N_{s} \times V_{\text {Cell }} \\
C_{\text {Module }}=\frac{C_{\text {Cell }}}{N_{s}} .
\end{gathered}
$$

Fig. 18 shows the voltage and current profiles of the supercapacitor of Company A for the FTP-72 UDDS. As shown in the figure, the maximum output current of the supercapacitor does not exceed $12 \%$ of the short circuit current, 4600A. Also, the voltage of the supercapacitor module does not drop below half of the full charge voltage, verifying the suitability of the design using (17) and (18).

As described above, the energy profile of the supercapacitor to drive one cycle of the FTP-72 UDDS can be obtained by integrating equation (15), and the profile varies depending on the supercapacitor efficiency. Therefore, the number of cells in a module varies by manufacturer due to the fact that the available energy values measured are different depending on the manufacturer. Thus the number of cells to compose a module also varies by manufacturer. The number of cells required to compose a module with different supercapacitors are shown in Table IV. It can be seen that the product of Company D needs 33 cells in a module while the product of Company $\mathrm{C}$ only needs 20 cells, which is significantly lower.

Fig. 19 shows the energy profiles of the supercapacitors by manufacturer during the course of one FTP-72 UDDS. The obtained results are different depending on the manufacturer. However, it is easily seen that the charge of the supercapacitor after one cycle is reduced, meaning that extra energy, other than the regenerative energy, is needed to restore the charge

TABLE IV

Comparison of Number of Cells in a Module

\begin{tabular}{|c|c|c|c|c|}
\hline Manufacturers & $\mathrm{A}$ & $\mathrm{B}$ & $\mathrm{C}$ & $\mathrm{D}$ \\
\hline $\mathbf{E}_{\text {needed }}[\mathbf{k J}]$ & 177.5 & 185.0 & 179.6 & 199.6 \\
\hline $\mathbf{E}_{A_{-} E X}[\mathbf{J}]$ & 8005 & 8575 & 9279 & 6140 \\
\hline $\mathbf{N}_{s}$ & 23 & 22 & 20 & 33 \\
\hline
\end{tabular}




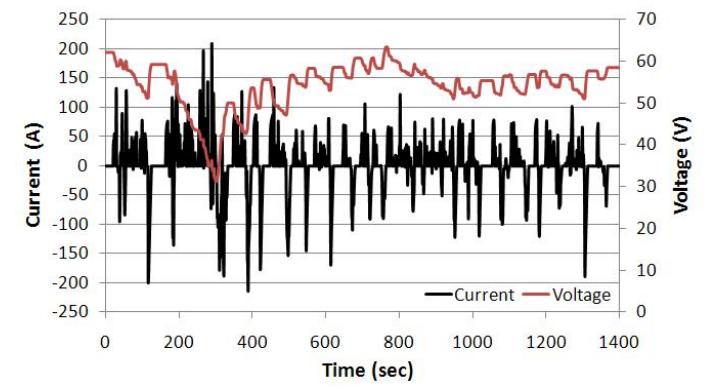

Fig. 18. Voltage and current profiles of the supercapacitor of the Company A for FTP-72 UDDS.

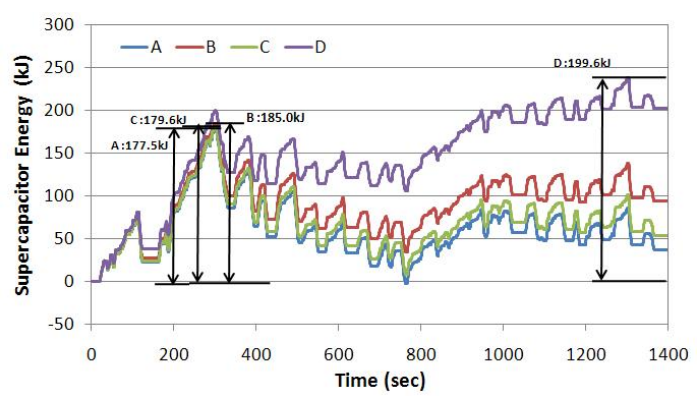

Fig. 19. Energy profiles of the supercapacitors by manufacturer.

of the supercapacitor for the next cycle. Also, the amount of energy required to restore the charge of each supercapacitor is different. The product of Company D is the worst and this is due to the fact that it has the lowest charge/discharge efficiency as previously shown in Table III. Even though the number of cells in a module is lowest with product of Company $\mathrm{C}$, the product of Company $\mathrm{A}$ is preferred due to its high charge/discharge efficiency.

To validate the simulation result, a miniaturized supercapacitor power profile for FTP-71 UDDS operation, as shown in Fig. 16, has been tested for a manufactured supercapacitor. Considering the charge/discharge efficiency of the manufactured supercapacitor, the calculated supercapacitor power profile was divided by the number of cells (calculated from Table V) to calculate the power supplied to each cell, and this was miniaturized to the $1 / 20$ scale. In addition, by using a BP4610 bipolar power supply (NF Corporation) the current was controlled in real time using a PCI-6154 (NI Corporation) data acquisition device, and the voltage of the supercapacitor was measured. Fig. 20 shows the voltage of the supercapacitor during the operation of the FTP-72 UDDS. It can be confirmed that a product with a high charge/discharge efficiency maintains a high state of charge condition after one cycle is completed. Here, in the case of the product manufactured by Company D, it can be seen that the dynamic characteristics of the response voltage vary considerably when compared to those in products manufactured by competitors. This is because the voltage change caused by the ESR is relatively greater when compared to the voltage variance caused by the charge/discharge current, which is scaled down to the 1/20 scale because of the high ESR value of product D.

\section{CONCLUSIONS}

In this paper, selection criteria for a supercapacitor based on a performance evaluation were proposed. Supercapacitors by

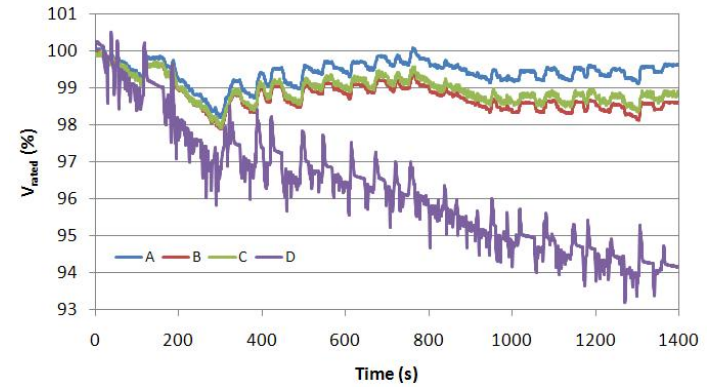

Fig. 20. Experimental result of the supercapacitor response voltage during FTP-72 UDDS.

various manufacturers were analyzed through an EIS experiment and the dynamic characteristics were compared to select the best product. The usefulness of the proposed selection criteria were then verified through computer simulations and experiments with the FTP-72 UDDS driving cycle of a fuel cell vehicle using supercapacitor modules. It is anticipated that if the proposed method is used, the system price can be reduced and economic profit raised through optimal selection of supercapacitors in composing large capacity systems that use supercapacitor modules.

\section{ACKNOWLEDGMENT}

This work has been supported by KESRI (2008T100100162), which is funded by Ministry of Knowledge Economy (MKE).

This work (research) was financially supported by the Ministry of Knowledge Economy (MKE) and Korea Institute for Advancement in Technology (KIAT) through the Workforce Development Program in Strategic Technology.

This work was supported by the 20104010100610 of the Korea Insitute of Energy Technology Evaluation and Planning (KETEP) grant funded by the Ministry of Knowledge Economy, Republic of Korea.

\section{REFERENCES}

[1] B. E. Conway, Electrochemical Supercapacitor: Scientific Principles and Technological Applications, Plenum, New York, NY, 1999.

[2] M. Ortúzar, J. Moreno, and J. Dixon, "Ultracapacitor-based auxiliary energy system for an electric vehicle: implementation and evaluation," IEEE Trans. Ind. Electron., Vol. 54, No. 4, pp.3225-3233, Aug. 2007.

[3] J. Moreno, M. E. Ortúzar, and J. W. Dixon "Energy-management system for a hybrid electric vehicle, using ultracapacitors and neural networks," IEEE Trans. Ind. Electron., Vol. 53, No. 2, pp.614-623, Apr. 2006.

[4] A. Emadi, Y. J. Lee, and K. Rajashekara, "Power electronics and motor drives in electric hybrid electric and plug-in hybrid electric vehicles," IEEE Trans. Ind. Electron., Vol. 55, No. 6, pp.2237-2245, Jun. 2008.

[5] S. M. Lukic, J. Cao, R. C. Bansal, F. Rodriguez, and A. Emadi, "Energy storage systems for automotive applications," IEEE Trans. Ind. Electron., Vol. 55, pp.2258-2267, Jun. 2008.

[6] P. Thounthong, S. Rael, and B. Davat, "Control strategy of fuel cell and supercapacitors association for a distributed generation system," IEEE Trans. Ind. Electron., Vol. 54, pp. 255-3233, Dec. 2007.

[7] M. Uzunoglu and M. S. Alam, " Modeling and analysis of an FC/UC hybrid vehicular power system using a novel-wavelet-based load charing algorithm," IEEE Trans. Energy Convers., Vol. 23, No. 1, pp. 263-272, Mar. 2008.

[8] L. Zubieta and R. Bonert, "Characterization of double-layer capacitors for power electronics applications," IEEE Trans. Ind. Electron., Vol. 36, pp. 199-205, Jan./Feb. 2000. 
[9] H. Gualous, D. Bouquain, A. Berthon, and J. M. Kauffmann, "Experimental study of supercapacitor serial resistance and capacitance variations with temperature," J. Power Sources, Vol. 123, pp. 86-93, Sep. 2003.

[10] S. Buller, E. Karden, D. Kok, and R. W. De Doncker, "Modeling the dynamic behavior of supercapacitors using impedance spectroscopy," IEEE Trans. Ind. Applicat., Vol. 38, pp. 1622-1626, Nov./Dec. 2002.

[11] NF BP4610 Instruction Manual, NF Corporation.

[12] J. Lee and W. Choi, "Development of the low-cost impedance spectroscopy system for modeling the electrochemical power sources," The 7th ICPE,, pp. 113-118, Oct. 2007.

[13] NI 6124/6154 User Manual, National Instruments Corporation, 2008

[14] R. De Levie, Electrochemical Response of Porous and Rough Electrodes, Advances in Electrochemistry and Electrochemical Engineering, Vol. 6, Wiley Interscience, New York, 1967.

[15] O. Bohlen, J. Kowal, and D. U. Sauer, "Ageing behaviour of electrochemical double layer capacitors Part I. Experimental study and ageing model," J. Power Sources, Vol. 172, pp. 468-475, Oct. 2007.

[16] O. Bohlen, J. Kowal, and D. U. Sauer, "Ageing behaviour of electrochemical double layer capacitors Part II. Lifetime simulation model for dynamic applications," J. Power Sources, vol. 173, pp. 626-632, Nov. 2007.

[17] F .Rafik, H. Gualous, R. Gallay, A. Crausaz, and A. Berthon, "Frequency, thermal and voltage supercapacitor characterization and modeling," J. Power Sources, Vol. 165, pp. 928-934, Mar. 2007.

[18] H. E. Brouji, J.-M. Vinassa, O. Briat, N. Bertrand, and E. Woirgard, "Ultracapacitors self discharge modelling using a physical description of porous electrode impedance," IEEE Vehicles Power and Propulsion Conf., Sep. 2008.
[19] A. Salkind, T. Atwater, P. Singh, S. Nelatury, S. Damodar, C. Fennie Jr, and D. Reisner, "Dynamic characterization of small lead-acid cells," $J$. Power Sources, Vol. 96 , pp. 151-159, Jun. 2001.

[20] Y. Cheng, J. V. Mierlo, P. Lataire, and G. Maggetto, "Test bench of hybrid electric vehicle with the super capacitor based energy storage," IEEE-ISIE'07, Jun. 2007.

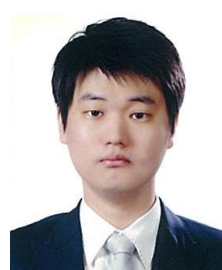

Sang-Hyun Kim was born in Seoul, Republic of Korea, in 1981. He received his B.S. and M.S. in Electrical Engineering from Soongsil University, Republic of Korea, in 2008 and 2010, respectively. He is currently a Research Engineer of the Power Electronics Technology Team, POSCO ICT, Republic of Korea. His current research interests include energy storage systems and grid-connected inverters.

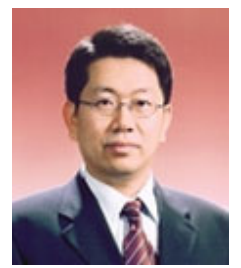

Woojin Choi was born in Seoul, Republic of Korea, in 1967. He received his B.S. and M.S. in Electrical Engineering from Soongsil University, Republic of Korea, in 1990 and 1995, respectively. He received his Ph.D. in Electrical Engineering from Texas A\&M University, USA, in 2004. From 1995 to 1998, he was with Daewoo Heavy Industries as a Research Engineer. His current research interests include the modeling and control of electrochemical energy sources such as fuel cells, batteries and supercapacitors, power conditioning technologies in renewable energy systems, and dc-dc converters for fuel cells and hybrid electric vehicles. 